\title{
BEBIDA FERMENTADA A PARTIR DE PIJUAYO (Bactris gasipaes H.B.K.) PARAMETROS Y EVALUACION
}

\author{
Victor Sotero* \\ Dora García *
}

Edson Lessi ${ }^{* *}$

\section{RESUMEN}

A partir del fruto del "Pijuayo" (Bactris gasipaes H.B.K.), raza "M acrocarpa" Putumayo, color anaranjado, se preparó una bebida conocida popularmente como "masato" en el Perú, por fermentación espontánea de la masa del mesocarpio colocado en vasos de precipitación de 2 litros, por un período de 6 días a la sombra, y temperatura ambiente $\left({ }^{ \pm} 30^{\circ} \mathrm{C}\right)$. L a masa fermentada fue diluida en solución de azúcar de 10 Brix, en la proporción de 1:2, seguidamente fue embotellada y pasteurizada. obteniéndose una bebida de excelentes características organolépticas, de color anaranjado de $\mathrm{pH}: 4$, acidez total de 24 $\mathrm{ml}$ de solución normal de $\mathrm{NaOH} \%$ y $1-5 \%$ vol de alcohol.

\section{ABST RACT}

From the "Pijuayo" (Bactris gasipaes H.B.K.) from the "M acrocarpa" Putumayo landrace, orange colour, was prepared a drink, populary called "masato" in Perú, by 6 days, spontaneous fermentation of cooked, ground pijuayo mesocarp in a 2 liter jar, the drink was then prepared by diluting this mash in a 10 Brix solution in a proportion of $1: 2$, followed by bottling and pasteurization. The "masato" presented good organoleptic characteristics, with agreable smell and flavour of orange colour, $\mathrm{pH}: 4$, total acid of $24 \mathrm{ml}$, normal sol. of $\mathrm{NaOH} \%$ and $1.5 \%$ vol alcohol.

Palabras Claves: "Pijuayo", fermentación, bebida fermentada.

Universidad Nacional de la A mazonía Peruana A pdo 611 - Iquitos - Perú

Instituto Nacional de Pesquisa de la Amazonía (INPA). Av. Cosme Ferreira, 1756-Manaus-AM-

Brasil 


\section{INTRODUCCION}

El Pijuayo, es una palmera nativa de la A mazonía, adaptada a las diferentes condiciones ecológicas del Trópico. Fué domesticada por los nativos desde los tiempos precolombinos en las tierras bajas de los neotrópicos húmedos. Se le encuentra desde Honduras hasta Bolivia, por tanto ocupa la mayor extensión del moderno neotrópico. (Clement, 1987; Mora Urpi et. al. 1982; Almeida \& M artin, 1980).

El fruto del "Pijuayo" ha despertado en los últimos años, una mayor atención de parte de los investigadores, por ser una importante fuente nutricional y de interés para el aprovechamiento industrial, aunque los resultados presentan valores diferentes como muestra el Cuadro $\mathrm{N} N 1$.

Cuadro No 1 Composición química del fruto de Pijuayo (B actris gasipaes H.B.K) según diferentes autores

FUENTE

$\%$ PESO SECO

Humedad Prot. Acei. Carb. Fibra Ceniza

$\begin{array}{lllllll}\text { ARCKOOL \& AGUILAR } & 55.7 & 6.8 & 23.0 & 59.5 & 9.3 & 1.3\end{array}$

Brasil, 1984

CHAVEZ et. al. 53.0

8.1

29.4

$42.3 \quad 18.5$

1.9

Brasil, 1949

JOHAN NESSEN

55.8

5.0

12.6

78.0

2.8

1.6

Costa Rica, 1967

ZAPATA

49.7

11.3

10.0

74.6

2.9

1.9

Colombia, 1972

PROMEDIOS

53.6

7.8

18.7

63.6

$8.3 \quad 1.6$ 
Patiño (1958), cita que los nativos de la A mazonía intertropical, preparaban una bebida a partir de la fermentación del Pijuayo. Esta es conocida como masato de pijuayo en el Perú y chicha de chontaduro en Colombia. BROWN (1968), relata que esta bebida es preparada primeramente por la cocción del fruto sin sal, y la molienda de la pulpa con plátanos. Esta mezcla es almacenada por dos o tres días, y en la porción semifermentada, puede ser diluida con agua. Este es luego dejado fermentar por un par de días, se le adiciona azúcar y es consumido. CALV O (1981), en Colombia, cita una receta sobre la preparación, incluyendo la adición de un fermento, y explica que la fermentación para refresco es de 10 horas, y para bebida alcohólica de dos a tres días.

\section{MATERIAL Y METODOS}

\subsection{M aterial}

Los frutos fueron colectados en el Banco Activo de Germoplasma de Pijuayo, localizado en la Estación Experimental de Fruticultura del Instituto $\mathrm{N}$ acional de Pesquisas de la A mazonía (INPA), en el Km. 39 de la carretera denominada BR-174, en el M unicipio de M anaus-AM -Brasil.

La colecta de los frutos se realizó en el período de octubre de 1987 a noviembre de 1988. Utilizándose para el presente trabajo la población denominada Putumayo. Cuya semilla fue colectada en las inmediaciones del río Putumayo.

\subsection{Análisis F ísico-químico}

Fueron retirados en forma aleatoria los frutos, para la preparación de las muestras y determinaciones físico-químicas. De estos frutos una parte sirvió para el análisis de humedad, y la otra para las determinaciones sobre materia

seca, como fueron aceite, proteína, ceniza, fibra y almidón, según las normas analíticas del Instituto A dolfo L utz (1985). 


\subsection{Proceso de elaboración de la Bebida Fermentada (Vino de Pijuayo)}

\subsubsection{L avado}

Se realizó utilizando agua potable, con la finalidad de eliminar la suciedad adherida a los frutos.

\subsubsection{Cocción}

Se cosieron durante dos horas, a la temperatura de $100^{\circ} \mathrm{C} \pm 1^{\circ} \mathrm{C}$, con el objeto de gelatinizar el almidón.

\subsubsection{Pelado y Despepado}

Se realizó en forma manual con cuchillos de acero inoxidable.

\subsubsection{M olienda}

Se realizó en molino de granos, en forma manual, obteniéndose una masa viscosa.

\subsubsection{Mezclado y Adición de Sacarosa}

A la pulpa molida, se le adiciona sacarosa (azúcar comercial blanca refinada), en la proporción de $37 \%$ y $50 \%$.

\subsubsection{Fermentación}

La mezcla (masa), se coloca en un vaso de precipitación de 2 litros, cubierto con un paño (o con tela), se deja fermentar por acción de las levaduras propias del Pijuayo, por un tiempo de 6 días a la temperatura del ambiente ( ${ }^{ \pm}$ $30^{\circ} \mathrm{C}$ ), en un lugar fresco y aireado, bajo techo. 


\subsubsection{Dilución y Adición de Azúcar}

Cumplido el tiempo de fermentación de masa, esta se diluye en una proporción de 1:2 con agua tratada, al cual se adiciona azúcar blanca refinada (sacarosa), en diferentes proporciones (hasta el 15\%), tratando que la bebida (vino), enmascare y no se exceda de dulzor.

\subsubsection{Decantación / Filtración}

La bebida diluida se deja reposar por un espacio aproximado de 2 horas, para sedimentar los sólidos presentes, y posteriormente se filtra con tela de tocuyo, para eliminar fibras y residuos sólidos.

\subsubsection{E mbotellado y Tapado}

L a bebida filtrada es embotellada y tapada herméticamente con tapas metálicas con fondo plástico.

\subsubsection{Pasteurización}

Las botellas con la bebida fueron colocadas en autoclave a $100^{\circ} \mathrm{C}$, por un período de 15 minutos.

\subsubsection{Enfriamiento}

Después de la pasteurización las botellas conteniendo el producto, fueron enfriadas en agua tibia a $70^{\circ} \mathrm{C}$. Posteriormente estas fueron almacenadas a temperatura ambiente.

\subsection{Análisis Físico-Químicos de la Bebida Fermentada}

Fueron realizados análisis antes y después de la fermentación. $L$ as botellas fueron analizadas 30 días después del procesamiento. 
Sobre la masa pre-fermentada y fermentada, se realizaron los siguientes análisis: $\mathrm{pH}$, almidón, azúcares reductores y no reductores, acidez total, titulable y fija, residuo seco y grados Brix, según las normas analíticas del Instituto A dolfo L utz (1985).

\subsection{Análisis M icrobiológico}

Fueron realizados análisis sobre las bebidas almacenadas a temperatura ambiente, después de 30,60 y 240 días. Se realizaron análisis de hongos y levaduras, según ICM SF (1982).

Se hicieron análisis de bacterias coniformes y microorganismos mesófilos según Thatcher \& Clark (1968).

\subsection{Análisis Sensorial}

El delineamiento estadístico empleado fué de bloques al "acaso", los resultados sometidos a análisis de varianza con la utilización de la prueba " $F$ ", habiéndose establecido el nivel de significancia de 5\%, M onteiro (1984). 
Fig. 1. Diagrama de flujo para el proceso de la bebida fermentada de Pijuayo (Bactris gasipaes H.B.K.)

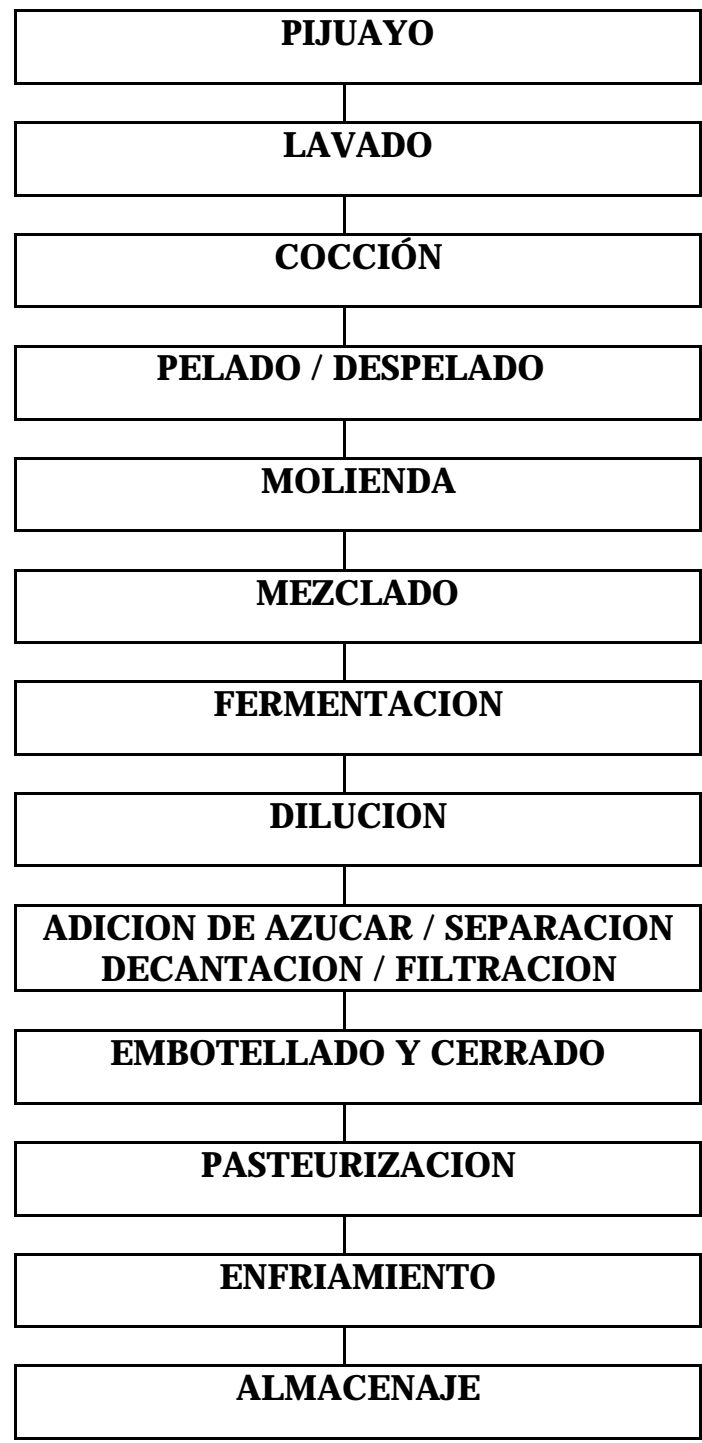




\section{RESULTADOS Y DISCUSION}

Para el procesamiento de la bebida fermentada de Pijuayo, se trabajó de acuerdo con el diagrama de flujo de la Fig. 1. El tiempo de cocción de los frutos enteros fué de 2 horas a temperatura de $100^{\circ} C^{ \pm} 10 \mathrm{C}$. Para otros productos amiláceos la temperatura de cocción son variables. Park \& Pastore (1986), señalan que para productos similares, la temperatura de cocción fué 140 $C$ a $180^{\circ} \mathrm{C}$. En el caso de la preparación del saqué, a partir de arroz, Pizzinato \& Srebernich (1983), afirman que el tiempo de cocción es de 60 minutos con vapor, y en este trabajo el tiempo de cocción se duplica.

La variación del pH y acidez titulable hasta el sexto día de fermentación, se dan en la Tabla $\mathrm{N}$ 1 . Esta interrupción se dá en función de la concentración de alcohol deseado y también debido a la experiencia indígena.

Se observó, que después de la fermentación hubo un pequeño aumento de la acidez titulable (Tabla $\mathrm{N}$ ㅇ 2). con relación a los azúcares de las masas de pijuayo cocida, utilizada en la fermentación se verificó que, los azúcares reductores presentes en la masa fueron totalmente convertidos durante el procesamiento en las dos proporciones. Los azúcares no reductores, adicionados en las proporciones de 37 a 50\%, fueron convertidos en la razón de 68.45 y $66.66 \%$ respectivamente. La conversión del almidón fue semejante en los dos casos: 43.35 y $41.98 \%$ respectivamente.

A poyados en la conversión de los azúcares no reductores adicionados en el almidón, en el volumen del alcohol obtenido, de la variación del $\mathrm{pH}$ y de la acidez titulable, fué seleccionada la fermentación de masa cocida de Pijuayo adicionada de $37 \%$ de azúcar.

L as determinaciones básicas de la bebida embotellada, se presentan en la Tabla $\mathrm{N} 0$ 3. Este producto presentó una acidez total de $2.4 \mathrm{ml}$ de solución normal de $\mathrm{NaOH} \%$ y acidez fija de $1.6 \mathrm{ml}$ de solución normal de $\mathrm{NaOH}$. El pH fué de 4.0, presentando poca diferencia con productos similares, como la cerveza ( $\mathrm{pH}$ entre 4 y 5) (Cereda in Aquarone et. al. 1986) y vinos (pH menor a 4) (Radler, 1986). $\mathrm{H}$ ashimzume in A quarone et. al. (op. cit). recomienda para este tipo de bebidas pH menores que 4, por cuanto así presenta esta una mejor resistencia a la infección bacteriana. 
Los carbohidratos totales en la bebida de Pijuayo son de $27 \%$, lo cual le da un al to contenido alimenticio, comparándolo con la cerveza que tiene $4.5 \%$ (Cereda in Aquarone et. al. 1986). A demás tiene una baja concentración alcohólica $(1.5 \%)$, estando más cerca de la cerveza (2 a $7 \%$ ) y menor que los vinos naturales (7 a 14\%) (AUSTIN 1988).

De acuerdo a los análisis microbiológicos, se puede afirmar que esta bebida es apta para su consumo, al no haber presentado alteración por efecto de microorganismos hasta 240 días después de su pasteurización.

La evaluación sensorial de la bebida (Tabla $\mathrm{N}$ o 4) destaca al producto cuyo contenido de azúcar agregada, tiene un máximo de 10\% en su composición.

TABLA No 1. Variación del pH y de la acidez titulable de la masa de Pijuayo raza "M acrocarpa" Putumayo, cocida y adicionada de $37 \%$ de azúcar, durante 6 días de fermentación espontánea.

\section{I A S}

ACIDEZ TITULABLE

$\mathrm{ml}$ sol normal $\mathrm{NaOH} \%$

0.50

1.10

0.51

0.6

0.50

0.8 
TABLA № 2 Características de las masas de Pijuayo (Bactris gasipaes H.B.K.) cocido, Raza M acrocarpa Putumayo, antes y después de seis días de fermentación espontánea.

\begin{tabular}{|c|c|c|c|c|}
\hline \multirow[b]{2}{*}{ DETERMINACIONES } & \multicolumn{4}{|c|}{ MASA COCIDA DE PIJUAYO } \\
\hline & $\begin{array}{l}\text { CON } 37 \% \text { DE } \\
\text { INICIAL }\end{array}$ & $\begin{array}{l}\text { AZUCAR } \\
\text { FINAL }\end{array}$ & $\begin{array}{c}\text { CON } 50 \% \text { DE AZ } \\
\text { INICIAL }\end{array}$ & $\begin{array}{l}\text { JCAR } \\
\text { FINAL }\end{array}$ \\
\hline $\begin{array}{l}\text { A cidez Titulable } \\
\text { ml.sol.N. NaOH v/p\% }\end{array}$ & 0,398 & 0,996 & 0,597 & 0,78 \\
\hline $\mathrm{pH}$ & 5,2 & 4,0 & 5,3 & 4,0 \\
\hline $\begin{array}{l}\text { A zúcares: } \\
\text {-R eductores } \\
\text {-No Reductores } \\
\text {-Almidón }\end{array}$ & $\begin{array}{r}1,78 \\
12,84 \\
32,20\end{array}$ & $\begin{array}{r}---05 \\
18,24\end{array}$ & $\begin{array}{r}1,78 \\
14,10 \\
32,20\end{array}$ & $\begin{array}{c}-\cdots--- \\
4,70 \\
18,68\end{array}$ \\
\hline Alcohol, Vol. \% & $-\cdots---$ & 3,0 & ----- & 3,0 \\
\hline Conversión de A zucares & ----- & 68,45 & $-\cdots---$ & 66,66 \\
\hline Conversión de Almidón & ----- & 43,35 & ----- & 41,98 \\
\hline
\end{tabular}


TABLA No 3. Determinación básica de la bebida fermentada del Pijuayo raza "Macrocarpa" Putumayo, fermentado con 37\% de azúcar y diluido 2:1 en solución al 10\% de azúcar.

Rendimientos de la masa fermentada

Pulpa útil / fruto\%

65.0

Litros / árbol

Litros / ha $340,000.0$

Producto embotellado

A cidez $\%$

Titulable ( $\mathrm{ml}$ de sol normal de $\mathrm{NaOH} \%$ )

Total ( $\mathrm{ml}$ de sol normal de $\mathrm{NaOH} \%$ )

2.4

Fija (ml de sol normal de $\mathrm{NaOH} \%$ )

1.6

$\mathrm{pH}$

4.0

Carbohidratos Totales\%

27.0

A zucares reductores \%

Azucares no reductores \%

6.2

Almidón

18.4

Alcohol \% vol

Residuo seco

21.85

Brix

Densidad $\mathrm{g} / \mathrm{cm}^{3}$ 
TABLA No 4. A nálisis sensoriales de la bebida fermentada de Pijuayo, diluida en solución a $10 \%$ y $15 \%$ de azúcar.

CARACTERIST.(*) APARIENCIA COLOR SABOR OLOR TEXTURA MUESTRA

\begin{tabular}{llllll}
\hline & & & & & \\
10 & 4.6 & 4.6 & 4.2 & 4.2 & 4.3 \\
15 & 4.4 & 4.2 & 2.8 & 4.0 & 4.0 \\
\hline $\mathrm{F}$ & $0.66 \mathrm{~b}$ & $1.76 \mathrm{~b}$ & $140 \mathrm{a}$ & $2 \mathrm{~b}$ & $0.59 \mathrm{~b}$ \\
\hline
\end{tabular}

(*) Las escalas variaron de 1 a 5 puntos para 10 probadores.

a Significativo al nivel de $5 \%$.

b No significativo. 


\section{BIBLIOGRAFIA}

ALMEIDA, N \& MARTIN, F. W. Cultivation of neglected tropical fruits with promise. Parta. 8. the pejibaye U.S. Departament of Agriculture Science and Education Administration. 10 p. 1980.

A QUARONE, E.; LIMA, V. DE A. \& BORZANI, W. Botecnología: Alimentos y Bebidas producidas por fermentaçâo. Saô Paulo. Ed. Edgar Blucker. v 5. pp. 44 - 78, 1986.

ARKCOOL, D.B. \& AGUIAR, V.P.L. Peach palm (Bactris gasipaes H.B.K) a new source for vegetable oil from the wet tropical J. Sci. Food A gric. 35, pp. $520-526,1980$.

AUSTIN, G. T. Manual de procesos químicos en la industria $3^{\text {a }}$ Ed. M c. Graw Hill. pp. 677 - 703, 1989.

BROW N, the uses of pejibaye. s.n.t. 15 p. Costa Rica. 1963.

CALVO, J.M. U ses culinarios del chontadura. Colombia Fundación para la Educación Superior. 73 p. 1981.

CLEM ENT,C.R. Pupunha: una árvore domesticada Ciencia Hoje 5 (29) : pp. 43 - 49. 1987.

INTERNATIONAL COMMISSION OF MICROBIOLOGICAL SPECIFICATIONS FOR FOODS. Microorganism in foods their significance and methods of enumeration. 2 ed. Toronto. VI. pp. 158 - 159, 1982.

INSTITUTO ADOLFO LUTZ. Normas analíticas do Instituto Adolfo Lutz; métodos químicos y físicos para análirse de alimentos. 2 ed. Sâo Paulo. VI. 583 p. 1985.

JOHANNESSEN, C. L. Pejibaye palm: physical and chemical analysis of the fruit. Econ. Bot. 21 (4): pp. 371 - 378, 1967. 
MONTEIRO, C.L.B. Técnicas de avaliaçâo sensorial. Ed.Curitiva. Centro de Pesquisa e Processamiento de A limentos. U niversidad Federal do Paraná pp. $12-83,1980$.

MORA URPI et. Al. 1992. El pijuayo. Costa Rica. Bco. Nacional Costa Rica/ U niversidad de Costa rica. $11 \mathrm{pp}$.

PARK Y.K. \& PASTORE, G. M. Recente atualização de etanol a partir de amilaceos por métodos não convencionales. Bol SBCTA, 20 (314): pp. 181 194.

PATIÑO, V.M. El cachipay o pejibay (Bactris gasipaes Bailey) y su papel en la cultura y en la economía de los pueblos indígenas de A mérica intertropical. II. A m. Indig. 18 (4): pp. 299 - 332, 1958.

RADLER, F. Microbial biochemistry in $\mathrm{New}$ Progress in vine and wine research. Experienta, 4 (8): 884 p.

THATCHER. I. S. \& CLARK, D. S. Microorganismo in Food. University of Toronto Press Canada. 1968 pp. 64 - 77.

ZAPATA, A. Pejibaye palm from the Pacific Cost of Colombia, a detailed chemical analysis. Econ. Bot. 26 (2): 156 p. 